\title{
Guía para Cultivar Vegetales en la Florida'
}

\author{
Sydney Park Brown, Danielle Treadwell, J. M. Stephens, y Susan Webb; traducido por \\ Francisco Rivera ${ }^{2}$
}

El cultivo de vegetales le ofrece aire fresco, exposición al sol, ejercicio, diversión, terapia emocional, alimentos frescos nutritivos, ahorros económicos y muchos otros beneficios (Figura 1). Los vegetales pueden crecer durante todo el año en el estado de Florida si se les presta atención a las fechas de siembra correspondientes (Tabla 1). Aunque en esta guía provea recomendaciones principalmente para huertos tradicionales en el hogar, la información puede resultar útil para varios escenarios como es el desarrollo de huertos comunitarios, los huertos de mercados agrícolas y proyectos de jardinería no-convencionales, como huertos en recipientes o en bancos elevados (consulte la publicación de EDIS ENH1211, Gardening in Raised Beds (https://edis. ifas.ufl.edu/ep472).

\section{Pasos para Cultivar Vegetales} \section{Localización}

Para mayor comodidad, construya el huerto cerca del hogar en un lugar con buen drenaje cerca de una fuente de agua y en un área que reciba al menos seis horas de luz solar directa todos los días. Con el cuidado adecuado, también, puede incluir los vegetales en la huerta entre las plantas ornamentales. También, son adecuados los laterales de algunos lotes residenciales, donde haya luz directa por el tiempo señalado anteriormente. Cuando sea posible, rote los cultivos del huerto de un lugar a otro para controlar las enfermedades del suelo y otras plagas.

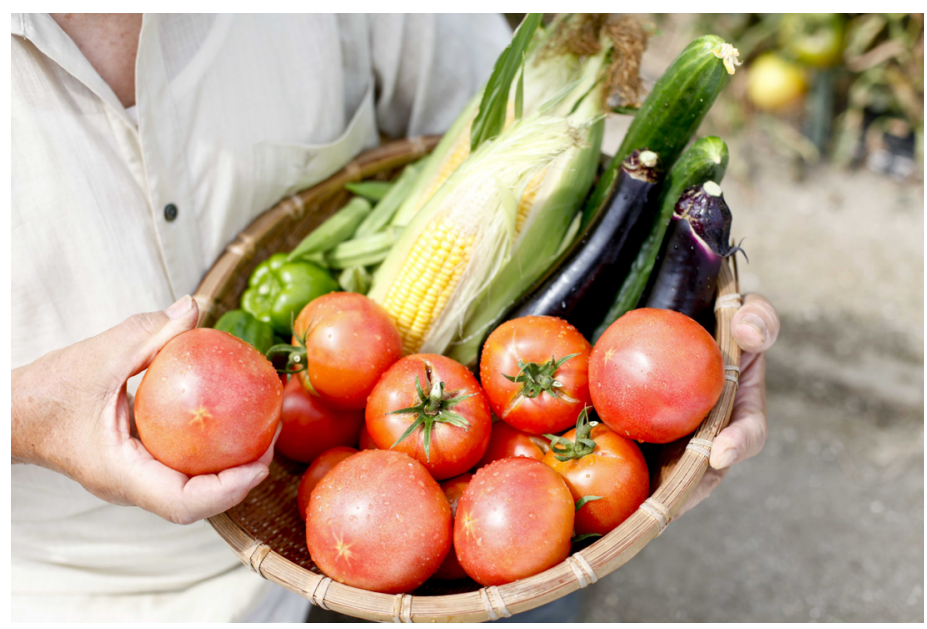

Figura 1.

\section{Planificación}

Antes de plantar, haga la planificación del huerto donde incluya el nombre, la ubicación y las fechas de plantación de los vegetales que quiere cosechar. Use la guía de plantación (Tabla 1) para planificar. Antes de comenzar su haga una

1. Este documento es SP103-SPA, uno de una serie del Horticultural Sciences Department, UF/IFAS Extension. Publicación original diciembre 1999. Revisado mayo 2018. Traducido septiembre 2020. Visite el sitio web de EDIS https://edis.ifas.ufl.edu.

2. Sydney Park Brown, associate professor emerita, Environmental Horticulture Department, and adjunct professor, Center for Landscape Conservation and Ecology; Danielle Treadwell, associate professor, Horticultural Sciences Department, and organic farming specialist; J. M. Stephens, professor emeritus, Horticultural Sciences Department; and Susan Webb, associate professor emerita, Department of Entomology and Nematology; UF/IFAS Extension, Gainesville, FL 32611.

El uso de nombres comerciales en esta publicación es solamente con el propósito de proporcionar información específica. UF/IFAS no garantiza ni recomienda los productos nombrados, y las referencias a ellos en esta publicación no significa nuestra aprobación a la exclusión de otros productos de composición adecuada.

The Institute of Food and Agricultural Sciences (IFAS) is an Equal Opportunity Institution authorized to provide research, educational information and other services

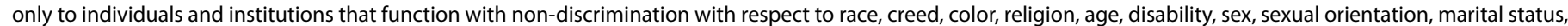

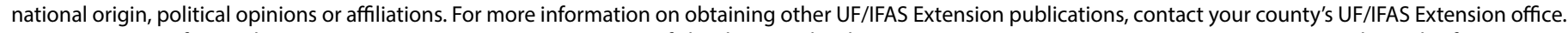
U.S. Department of Agriculture, UF/IFAS Extension Service, University of Florida, IFAS, Florida A \& M University Cooperative Extension Program, and Boards of County Commissioners Cooperating. Nick T. Place, dean for UF/IFAS Extension. 
lista de los materiales y tenga las semillas disponibles para cultivar, si tiene pensado cosechar sus propios trasplantes. En la guía de plantación hay un listado de las plántulas de vegetales de acuerdo a su facilidad para ser trasplantadas. Los vegetales que son difíciles de trasplantar deben sembrarse en recipientes primero o directamente en el huerto.

\section{Preparación del terreno}

Los jardineros a menudo plantan sobre cualquier tipo de suelo que esté disponible, pero por lo general resulta útil mejorar la composición del terreno agregando materia orgánica (vea más abajo). Cave o labre la parcela durante al menos tres semanas antes de plantar. En el momento de plantar, vuelva a trabajar el suelo hasta lograr una superficie uniforme y firme.

\section{Materia orgánica}

La mayoría de los suelos de Florida tienen poca materia orgánica y, por lo tanto, se mejoran al añadir composta de estiércol de animales, hojas en descomposición, composta de hongos, mezclas de tierra comerciales (mercadeados como potting mix) o cultivos de cobertura. Las materias orgánicas de composta pueden aplicarse al momento de la siembra; la materia orgánica no compostada (como gramas cortadas frescas) deben mezclarse con la tierra por lo menos un mes antes de sembrar. Debido a los niveles bajos e inconsistentes de los nutrientes en la composta, puede resultar útil la aplicación de fertilizantes inorgánicos u orgánicos (consulte "Fertilización” más abajo). Mezcle por completo los materiales orgánicos no compostados en el suelo mucho antes de la siembra, preferiblemente al menos un mes antes de sembrar. Si utiliza fertilizante basado en composta o estiercol de animales, asegúrese de esparcir entre 25 y 100 libras cada 100 pies cuadrados, y déjelo actuar en el suelo de 90 a 120 días antes de cosechar los vegetales. Consulte la publicación HS1215 de EDIS, Organic Vegetable Gardening in Florida (https://edis.ifas.ufl. edu/hs1215).

\section{Composta}

Cree su propio "oro negro" convirtiendo los desechos del patio en composta (Figura 2). La composta es fácil de hacer y produce un acondicionador de suelos o fertilizante orgánico similar al abono que beneficia en gran medida los suelos nativos poco fértiles de Florida. Consulte la publicación ENH 1065 de EDIS, Compost Tips for the Home Gardener (https://edis.ifas.ufl.edu/ep323).

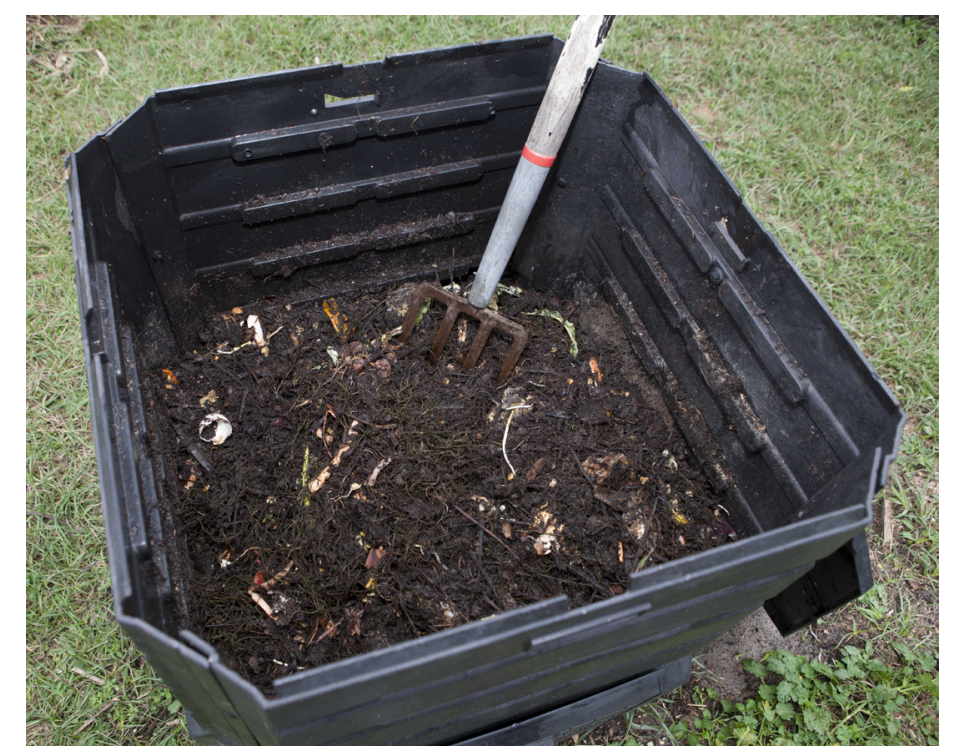

Figura 2.

Construya o compre una compostera. Usted puede construir una unidadcon paletas de madera reciclados, bloques de concreto, alambres resistentes, etc. El tamaño mínimo debe ser 3'Largo $\times$ 3'Ancho × 3'Alto.

Coloque una capa encima de otra de 12 pulgadas de grosor de desechos de plantas, como hojas, pasto cortado, ramas trituradas y virutas. También pueden usarse restos de comida.

Puede agregar estiercol de animales (no de mascotas), composta finalizado, harina de sangre o fertilizante a cada capa si así lo quiere.

Humedezca cada capa y mantenga húmeda la pila.

Voltee (o mezcle) la pila con frecuencia para que ingrese oxígeno y ayude en el proceso de descomposición.

Según como sea manejada la composta, debe estar lista para su uso entre dos y doce meses, cuando se hayan descompuesto las partes de las plantas.

Cubra la pila para evitar que la lluvia lixivie los nutrientes.

\section{Cultivos de cobertura (abono verde)}

Los cultivos de cobertura se pueden plantar fuera de estación para evitar la erosión, el crecimiento de malezas o la proliferación de nemátodos. Se recomiendan los siguientes cultivos de cobertura para los huertos de Florida:

- Verano: caupí, grano de terciopelo, soya y girasol

- Invierno: centeno de cereal (FL 401), trébol encarnado y arveja austriaca de invierno 
Cuando el cultivo de cobertura se pone en el suelo, la materia orgánica en descomposición (abono verde) suministra materia orgánica y nutrientes. Algunos cultivos de cobertura también pueden suprimir la población de nemátodos dañinos.

Para obtener más información, consulte las publicaciones ENY012 de EDIS, Nematode Management in the Vegetable Garden (https://edis.ifas.ufl.edu/ng005) y ENY059, Soil Organic Matter, Green Manures, and Cover Crops for Nematode Management (https://edis.ifas.ufl.edu/vh037).

\section{Ajuste del pH del suelo}

El pH del suelo es importante porque determina la disponibilidad de nutrientes para las plantas. El mejor rango de $\mathrm{pH}$ para los huertos de vegetales en suelos arenosos es un $\mathrm{pH}$ entre 5.8 y 6.3. Si el pH del suelo es entre 5.5 y 7.0, no es necesario hacer ningún ajuste al $\mathrm{pH}$.

Si el pH del suelo es inferior a 5.5, aplique cal al valor recomendado por un laboratorio de diagnóstico de suelos confiable, como el laboratorio de prueba de suelos de UF/ IFAS Extensión (https://soilslab.ifas.ufl.edu/). Poner entre dos y tres libras de cal dolomítica fina cada 100 pies cuadrados, por lo general, aumentará el pH un punto. Precaución: La aplicación de cal cuando no es necesario puede provocar problemas nutricionales en las plantas. Lo mejor es aplicar la cal entre dos y tres meses antes de plantar el huerto. Sin embargo, se puede aplicar la cal una o dos semanas antes de la siembra. Asegúrese de que la cal esté completamente mezclada en el suelo a una profundidad de 6 de 8 pulgadas y, luego, moje la tierra para promover la reacción química.

Si el pH de la tierra es generalmente superior a 7.0 (alcalino), y hay cali, roca calcárea o conchas presentes, no hay ninguna forma práctica de bajar el $\mathrm{pH}$ del suelo de forma permanente. Agregar materia orgánica ácida ayudará, pero solo parcialmente. Use un fertilizante que contenga micronutrientes. Si un pH alto es el resultado de la aplicación previa de cal en exceso, poner azufre granular $(1 \mathrm{lb} / 100$ pies cuadrados) disminuirá el pH del suelo.

\section{Fertilización}

A menos que se apliquen grandes cantidades de materia orgánica, generalmente se necesita un fertilizante sintético comercial para los huertos en Florida. A los jardineros les resulta cómodo usar los grados de fertilizantes generalmente disponibles, como 10-10-10. Sin embargo, algunos suelos de Florida contienen cantidades adecuadas de fósforo (el valor intermedio). Si este es el caso de su suelo, no se debe agregar más cantidad de este elemento debido a que el fósforo puede contaminar las aguas superficiales, como los lagos y ríos. Hacer una prueba del suelo permitirá saber la cantidad de fósforo y de otros nutrientes que deben aplicarse. Consulte la publicación de EDIS Cir. 1248, UF/ IFAS Extension Soil Testing Laboratory (ESTL) Analytical Procedures and Training Manual (https://ufdc.ufl.edu/ IR00003469/00001).

Utilice la cantidad de fertilizante adecuada basado en los resultados de la prueba del suelo. Coloque al voleo fertilizante sobre toda la era antes de la siembra. Durante la temporada de cultivo, se pueden aplicar 2 o 3 capas ligeras de fertilizante, según sea necesario. Aplique el fertilizante justo más allá de las hojas externas. Los vegetales de hoja como la lechuga, col rizada y berza se benefician de la aplicación lateral de fertilizante con nitrógeno, como el nitrato de amonio. Los cultivos tuberosos y de raíces, como las zanahorias y las patatas (o papas), responden al fertilizante potasio, como el muriato potásico.

Obtenga más información sobre fertilizantes orgánicos y manejo de nutrientes en la publicación de EDIS HS1215, Organic Vegetable Gardening in Florida (https://edis.ifas.ufl. edu/hs1215).

\section{Irrigación y drenaje}

Los vegetales no toleran el agua estancada proveniente de lluvias o la irrigación en exceso. Al mismo tiempo, los vegetales necesitan la humedad del suelo para crecer y producir. La frecuencia de irrigación depende de la edad del cultivo y del tipo de suelo. Las plantas más jóvenes necesitan una irrigación frecuente pero ligera; los cultivos maduros necesitan más agua pero con menos frecuencia. Los suelos arenosos exigen una irrigación más frecuente que suelos con alto contenido de arcilla, o suelos cenagosos, o los suelos previamente enmendados. Conserve el agua mediante el uso de fertilizantes, materia orgánica y técnicas como el riego por goteo. Presione ligeramente la base de las plantas para conservar el agua hasta que el suelo la absorba.

\section{Extensión de la temporada de los cultivos}

Los jardineros pueden extender la temporada de siembra con estructuras que reducen el estrés de las plantas y los daños provocados por temperaturas frías y cálidas. Los productores comerciales usan casas de sombra, túneles altos y cubiertas en fila; los jardineros pueden adoptar modificaciones de estos enfoques (Figura 3). Para obtener más información, consulte las siguientes publicaciones de EDIS Veggies and Herbs Made in the Shade (https://edis. ifas.ufl.edu/hs1228) y Row Covers for Growth Enhancement (https://edis.ifas.ufl.edu/cv106). Quite las cubiertas cuando 
las plantas que necesitan abejas para la polinización comiencen a florecer (vea los vegetales que figuran en la Tabla 1 que son miembros de la familia de las calabazas o cucurbitáceas).

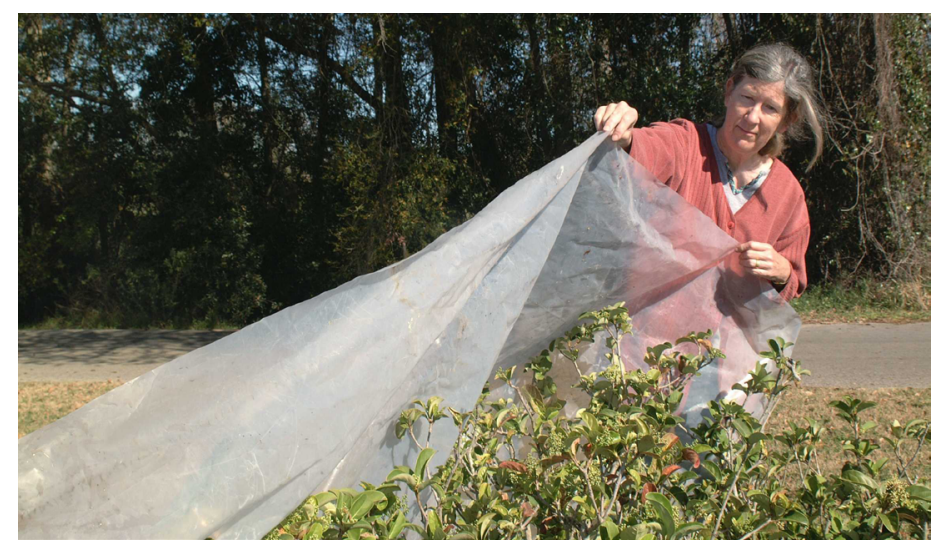

Figura 3.

\section{Manejo de Plagas}

Algunas de las plagas en los huertos son las malezas, los insectos, los ácaros, las enfermedades, los nemátodos, ardillas e incluso los animales como los mapaches y las aves que podrían consumir el cultivo de vegetales (consulte https://edis.ifas.ufl.edu/vh036).

Los jardineros tienen muchas opciones para reducir los problemas de plagas (https://edis.ifas.ufl.edu/in197). Los plaguisidas utilizados de manera indebida pueden ser perjudiciales para las personas, las mascotas, los insectos beneficiosos y el entorno natural. Su uso debe ser implementado tomando en cuenta otros métodos disponibles para el manejo integrado de plagas.

\section{Enfoques sin plaguicidas}

- Siga las fechas de siembra recomendadas para cada vegetal ubicado en la Tabla 1 . Sin embargo, tenga en consideración que los vegetales plantados a fines del verano o a inicios del otoño (agosto o septiembre) serán mas susceptibles a insectos y enfermedades que surgen en climas cálidos. También, los vegetales susceptibles a heladas plantados a fines del invierno o a principios de la primavera pueden sufrir daños por temperaturas bajo el punto de congelación o pueden sufrir daños severos si no se protegen con cubiertas (consulte arriba "Extensión de la temporada de los cultivos" para obtener más información sobre las cubiertas).

- Rote los cultivos para no plantar los mismos vegetales (o miembros de la misma familia de vegetales) en las mismas áreas evitando enfermedades. La familia de plantas de cada vegetal figura en la Tabla 1.
- Labre o voltee manualmente bien la tierra antes de la plantar para evitar los insectos del suelo, especialmente cuando el huerto es un área de césped convertida. Se debe voltear la tierra del huerto y no debe contener malezas, césped ni materiales de madera al menos 30 días antes de la siembra.

- Controle las malezas del huerto debido a que estas pueden ser una fuente de plagas y enfermedades. La maleza se controla mejor con la aplicación de una cubierta de plástico o vegetal y retirando manualmente o con azadón las hierbas indeseables. Las cubiertas vegetales recomendadas sonla paja, las hojas caídas y subproductos o remanentes de cosechas previas de vegetales. (composta no terminada). No se debe usar viruta ni aserrín no descompuesto. Se puede reducir la maleza en el exterior del huerto y entre las filas poniendo varias capas de periódico y, luego, cubriéndolo con hojas.

- Elija variedades adaptadas que sean resistentes o tolerantes a los nematodos, a las enfermedades habituales y acondiciones ambientales típicas de su área.

- Compre trasplantes saludables que no tengan insectos ni síntomas de enfermedades (como manchas de las hojas o plagas). Evite trasplantes que ya están floreciendo. Considere sembrar sus propios trasplantes con semillas (Figura 4).

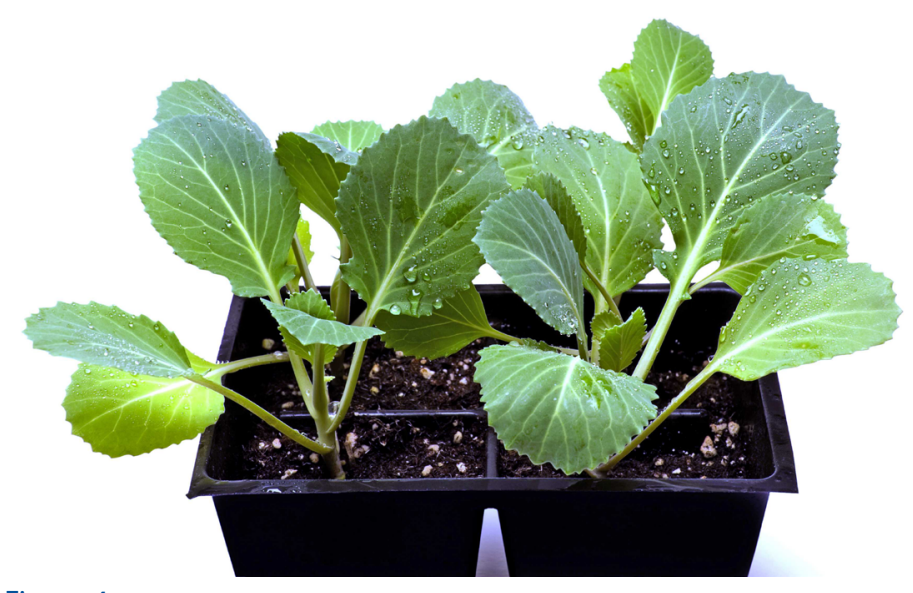

Figura 4.

- Proteja las plantas contra gusanos cortadores poniendo un protector alrededor de la planta. Puede hacer un protector con vasos de plástico sin fondo o con cajas de cartón enceradas. El protector debe extenderse algunas pulgadas por encima y al menos una pulgada por debajo de la superficie del suelo.

- Permita que las plantas crezcan vigorosa y saludablemente suministrando la cantidad de agua y fertilizante adecuada. Una planta saludable a menudo puede sobrevivir a los ataques de insectos. Demasiado nitrógeno, sin 
embargo, puede hacer que las plantas estén más expuestas a pulgones y moscas blancas.

- Inspección y Monitoreo es recomendado en el huerto dos veces por semana en busca de problemas de plagas. Esto implica inspeccionar las plantas desde los brotes hasta la tierra, incluyendo las superficies de hojas superiores e inferiores. Anote los problemas de plagas y el rendimiento de las diferentes variedades. Incluya fotografías de los insectos, las enfermedades y los insectos beneficiosos que encuentren en su huerto.

- Identifique los agentes beneficiosos (mantis religiosos, arañas, insectos de ojos grandes, insectos asesinos, mariquitas y todas las avispas). Algunos de estos artrópodos se pueden comprar, pero recuerde que ya existen naturalmente en Florida muchos insectos beneficiosos, $y$ se irán si no tienen plagas para comer.

- Siembre flores en el huerto de vegetales. Proporcionan néctar y polen que atraen a los insectos beneficiosos.

- Quite los insectos grandes manualmente y destrúyalos. Colóquelos en un recipiente con agua y jabón donde se hundan y ahoguen.

- Observe síntomas tempranos de las enfermedadades. Quite las hojas o plantas enfermas para evitar que se dispersen.

- No entre en pánico y comience a rociar ante el primer indicio de daños por insectos. La mayoría de las plantas que producen frutas, vainas o mazorcas pueden resistir de un $10 \%$ a un $20 \%$ la pérdida de hojas sin perder la potencial producción.

- Recolecte la cosecha de inmediato cuando este madura. Dejar las frutas sobremadurar en las plantas a menudo provoca más problemas de insectos.

- Quite las plantas no productivas y haga composta o deséchelas.

- Use la solarización del suelo para reducir los nemátodos, que son gusanos microscópicos que atacan las raíces de los vegetales y reducen el crecimiento y la producción. Esta técnica consiste en usar la energía del sol para calentar el suelo y matar las plagas. Para solarizar el suelo, primero quite la vegetación, luego rompa y humedezca el suelo para activar los nematodos. Cubra el suelo con una película de plástico transparente resistente a rayos ultravioletas. Coloque más tierra en los bordes para sujetar el plástico en su lugar. Se debe hacer la solarización durante las seis semanas de verano más cálidas. Se deben mantener altas temperaturas (superiores a $130^{\circ} \mathrm{F}$ ) para obtener mejores resultados. Consulte las publicaciones de
EDIS ENY012, Nematode Management in the Vegetable Garden (https://edis.ifas.ufl.edu/ng005).

- Agregue materia orgánica a la tierra para reducir las poblaciones de nemátodos. La materia orgánica mejora la capacidad del suelo de retener el agua y los nutrientes $y$, en consecuencia, mejora el vigor de las plantas y su resistencia a las plagas.

- Consulte también la publicación HS1215 de EDIS, Organic Vegetable Gardening in Florida (https://edis.ifas. ufl.edu/hs1215).

\section{Uso de plaguiscidas de manera inteligente}

Si opta por usar plaguscidas, consulte la Tabla 3 y siga las instrucciones de la etiqueta del pesticida cuidadosamente.

\section{- Use plaguicidas solamente cuando hay un problema} grave de plagas. En la oficina local de UF/IFAS Extension pueden proporcionarle información sobre la identificación de insectos. Los jardineros que se dedican a lo orgánico pueden usar algunos productos (microorganismos como el Bacillus thuringiensis, por ejemplo y otros https://edis.ifas.ufl.edu/in197).

- Proteja a las abejas y a otros polinizadores. Aplique insecticidas tarde durante el día cuando están menos activos. El malatión, el carbaril y las piretrinas son especialmente dañinos para las abejas (Figura 5).

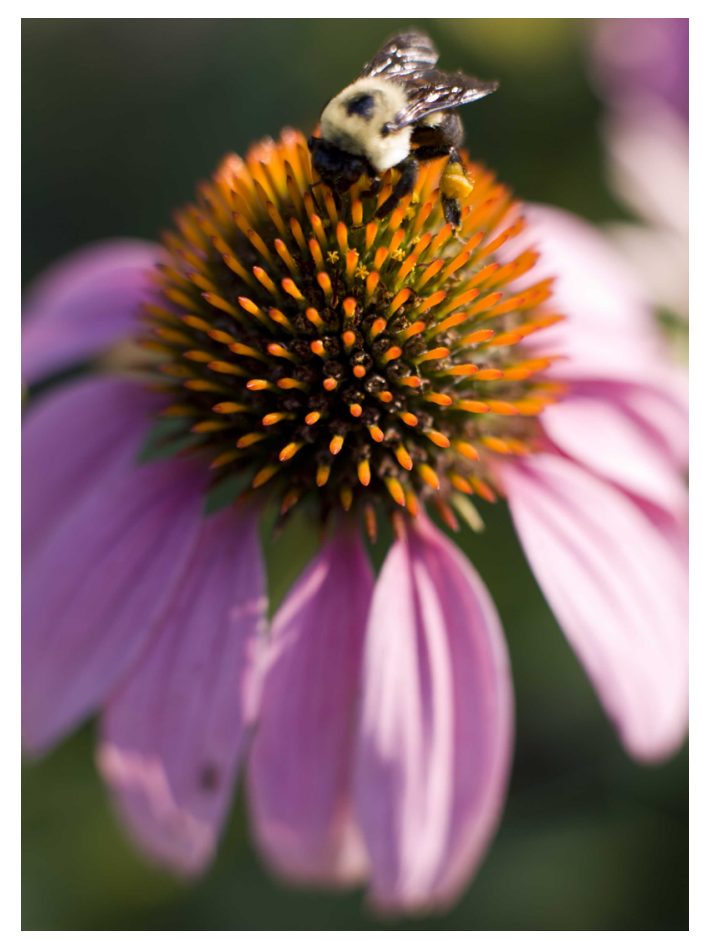

Figura 5. 
- Rocíe las plantas por completo, y cubra las superficies de las hojas superiores e inferiores.

\section{- No aplique pesticidas en días con viento.}

- Evite las quemaduras por rociado; asegúrese de que las plantas no estén bajo estrés por humedad. Riéguelas, de ser necesario, y deje que las hojas se sequen antes del rociado. Evite usar jabón y aceites cuando el clima es muy cálido.

- Controle las babosas con productos que contengan fosfato de hierro. Los productos con metaldehído como ingrediente activo son extremadamente tóxicos para los animales, como los perros y la vida salvaje que pueden atraer.

- Evite las enfermedades por hongos. Compre semillas tratadas con fungicidas. Muchas enfermedades se pueden controlar rociando fungicidas si las medidas de control comienzan de manera temprana, idealmente antes de que aparezcan los síntomas. Busque en la etiqueta los nombres de estas sustancias químicas en "ingredientes activos": clorotalonil, maneb o fungicida mancozeb. El añublo (moho polvoriento) se puede controlar con triadimenol, miclobutanil, azufre o aceites hortícolas. Las royas se pueden controlar con azufre, propiconazol o tebuconazol. Los productos en aerosol generalmente son más eficaces que los que vienen en polvo.

\section{- Lea la etiqueta.}

- No todos los pesticidas comerciales pueden usarse en todos los vegetales... Asegúrese de que aparezca el vegetal y la plaga en la etiqueta antes de comprar el producto

- Siga las instrucciones de la etiqueta para seguir las medidas seguridad y proporciones de mezclas y métodos para la aplicación necesarias para su cultivo.

- Preste especial atención a los "períodos de espera"; es decir, el tiempo que debe pasar entre la aplicación del plaguicida y la cosecha. Por ejemplo, no se debe cosechar brócoli al que se le ha rociado carbaril (Sevin) hasta pasadas dos semanas después de la aplicación.

- Siga todas las precauciones de seguridad que figuran en la etiqueta y asegúrese de que las personas y las mascotas se mantengan alejadas del área hasta que el producto rociado se seque.

Los agentes de UF/IFAS Extension se encuentran en cada condado de Florida para apoyarlo. Puede obtener la información de contacto en Find Your Local Office (https:// sfyl.ifas.ufl.edu/find-your-local-office/).

\section{Reconocimientos}

Los miembros del cuerpo docente retirados o reubicados que contribuyeron con la primera y la segunda revisión de esta publicación son R. A. Dunn, profesor retirado, Departamento de Entomología y Nematología de UF/IFAS; G. Kidder, profesor retirado, Departamento de Ciencias de la Tierra de UF/IFAS; D. Short, profesor retirado, Departamento de Entomología y Nematología de UF/IFAS; G. W. Simone, profesor retirado, Departamento de Patologías de Plantas de UF/IFAS; y Amanda Gevens, exasistente de profesor, Departamento de Patologías de Plantas de UF/ IFAS. 


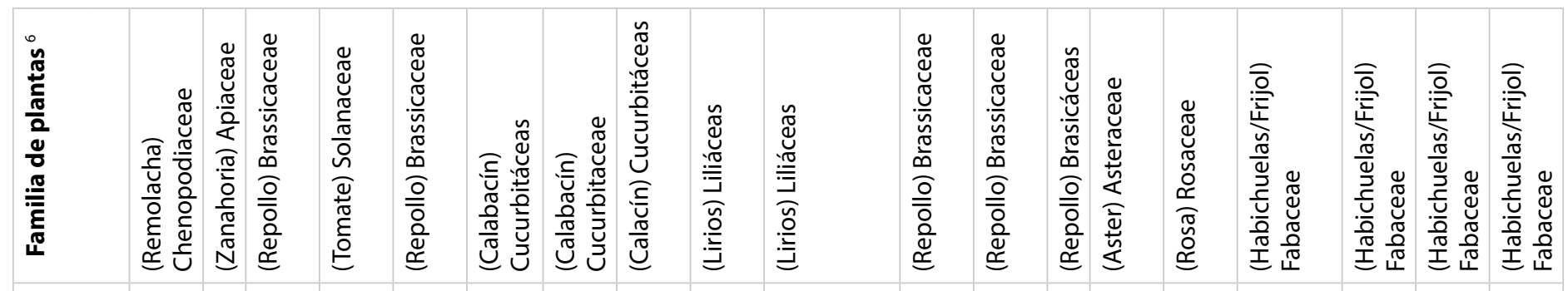

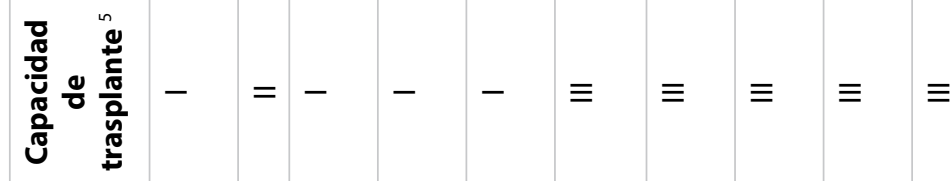

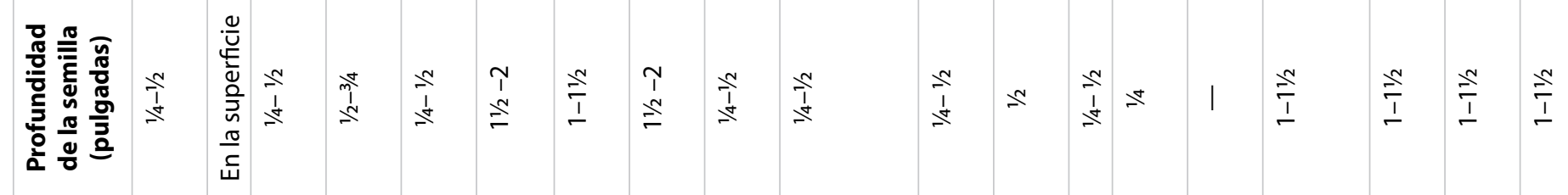

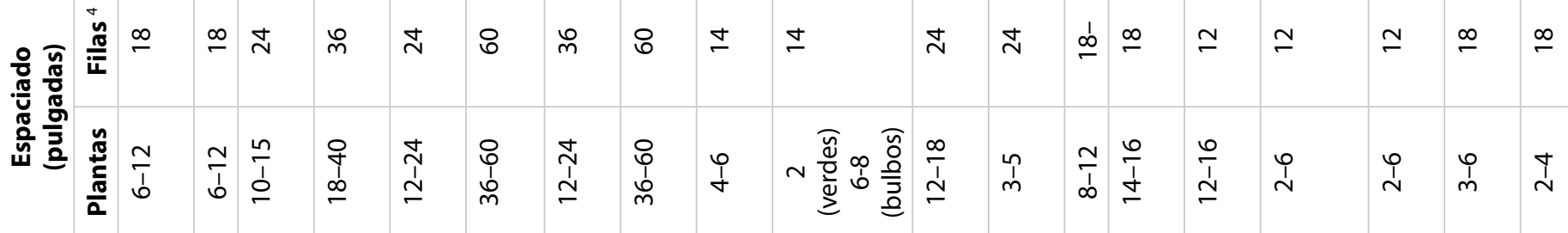

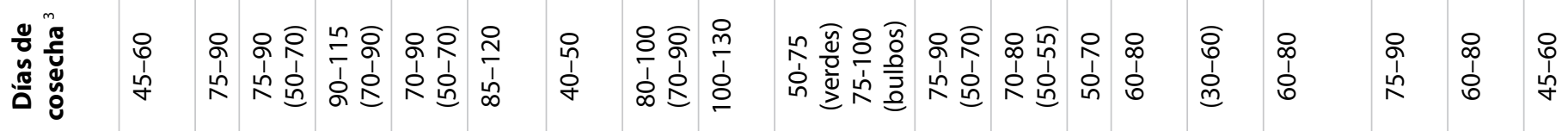

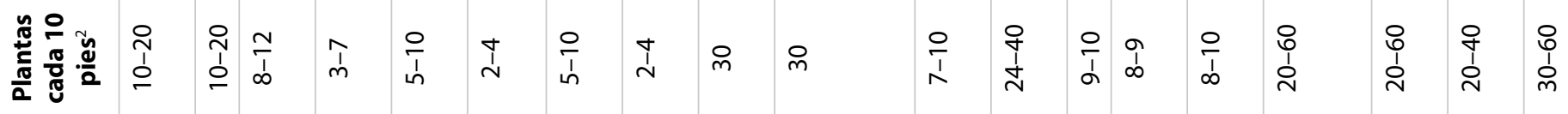

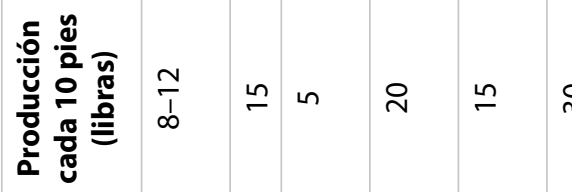

$\begin{array}{lllllll} & \\ 0\end{array}$



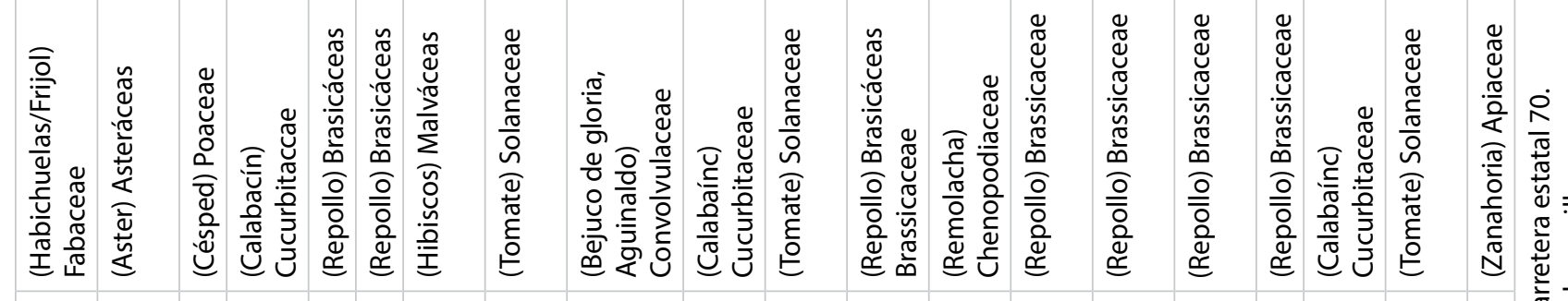

........

...

$-\equiv-=\frac{\frac{\pi}{0}}{\frac{0}{\partial}}$

율 $\frac{0}{2}$

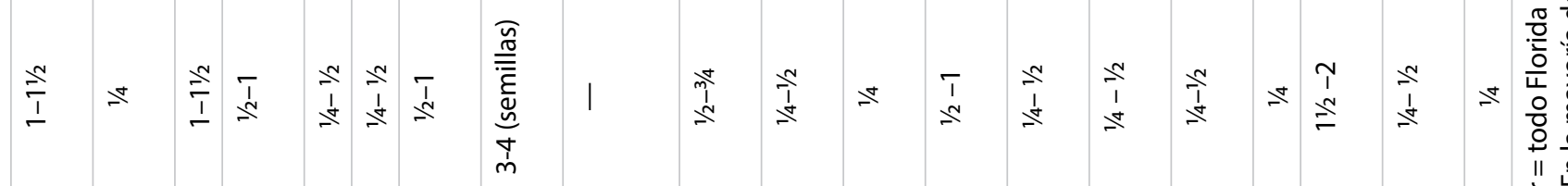

II ธᄄ

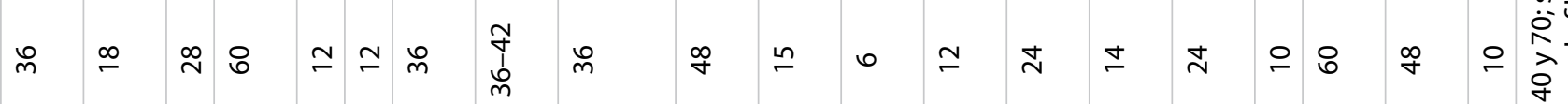

ラั

仓ั

约 $\frac{\pi}{2}$

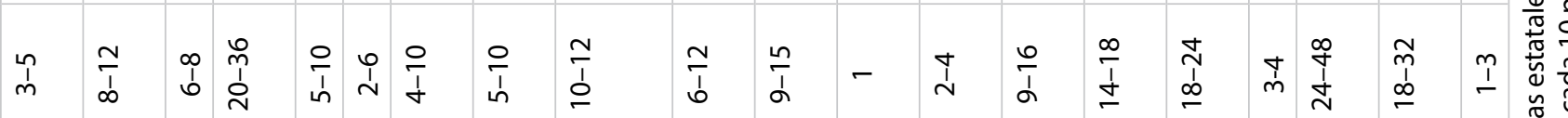

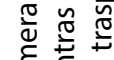

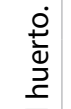
एँ

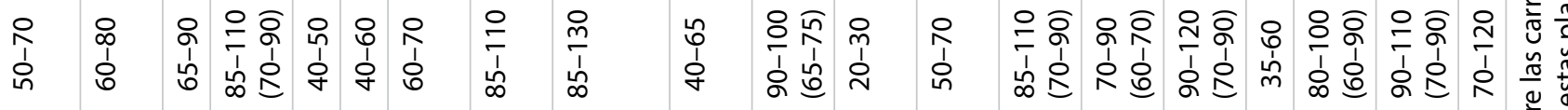
竎 $\frac{\frac{1}{0}}{2}$

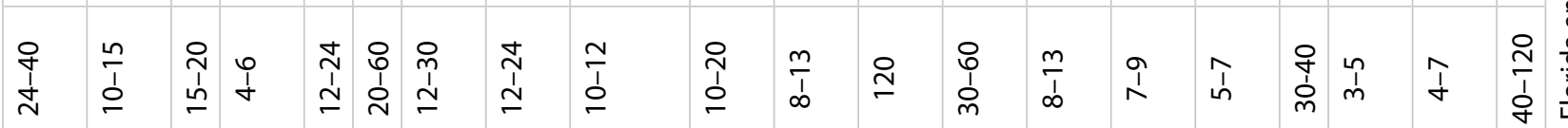
造 ⿺⿱一兀

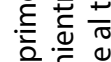

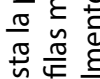

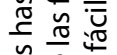

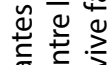

흥 व

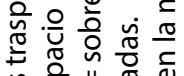

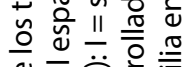

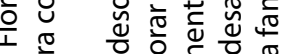

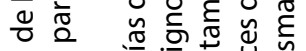
:든

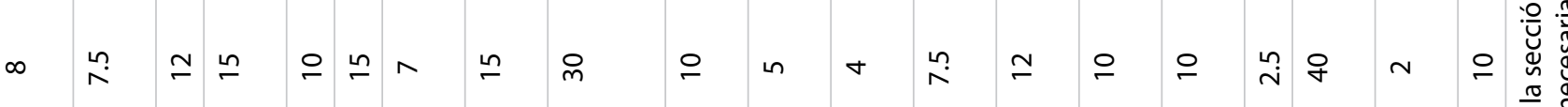

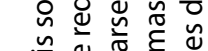

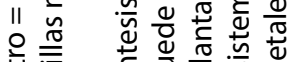

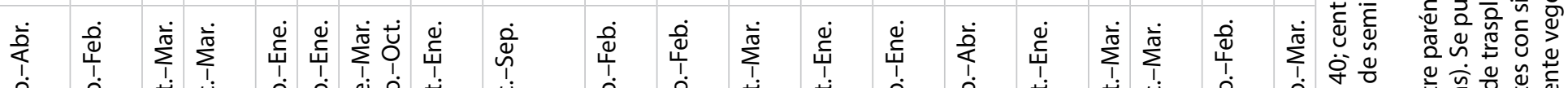

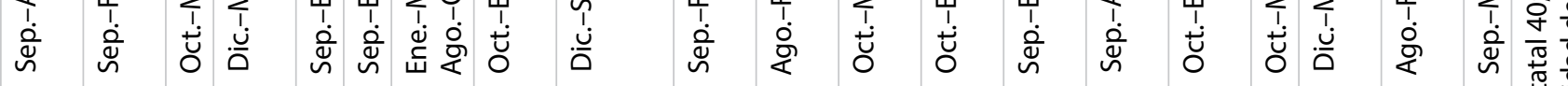

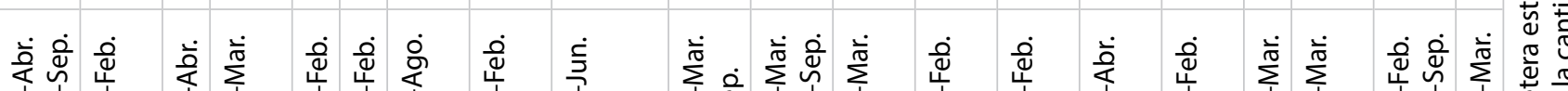

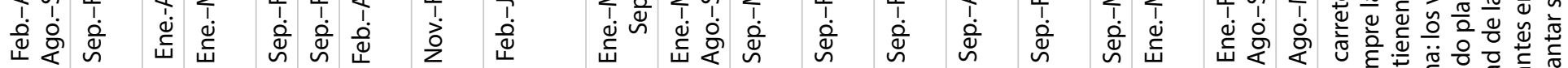

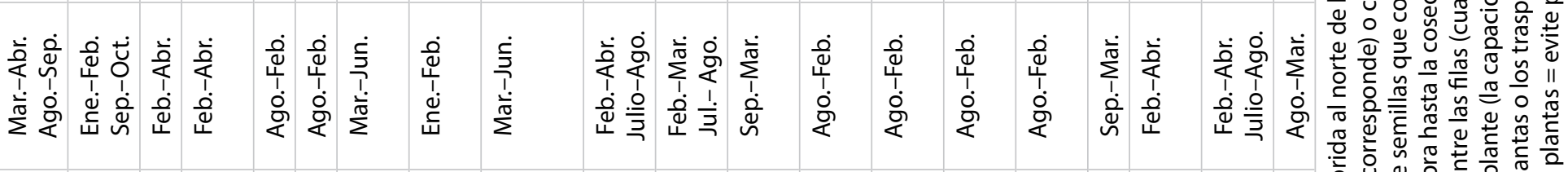

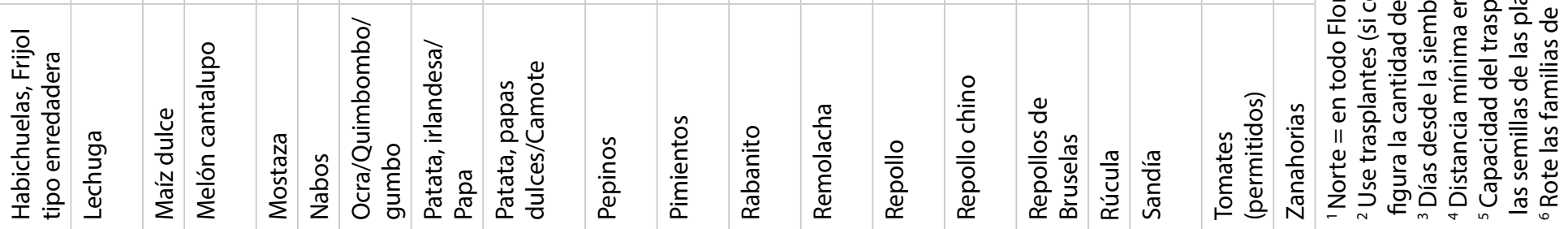


Tabla 2. Variedades sugeridas de huertos en Florida.

\begin{tabular}{|c|c|c|}
\hline CULTIVO & VARIEDADES RECOMENDADAS $^{1}$ & NOTAS/OBSERVACIONES \\
\hline Acelga suiza & $\begin{array}{l}\text { Bright Lights, Bright Yellow, } \\
\text { Fordhook Giant, Lucullus, Red } \\
\text { Ruby }\end{array}$ & $\begin{array}{l}\text { Se pueden sembrar las semillas en el otoño y a fines del invierno o a principios } \\
\text { de la primavera. Es un excelente vegetal de hoja para climas cálidos. Coseche las } \\
\text { hojas externas cuando tengan de } 8 \text { a } 10 \text { pulgadas de largo. Muy susceptibles a } \\
\text { nematodos de pudrición de las raíces. }\end{array}$ \\
\hline Apio & Variedades de Utah & $\begin{array}{l}\text { Puede ser difícil de cultivar en el huerto de su casa. Necesita suelos muy húmedos } \\
\text { durante la etapa de siembra y plántulas. Tiene un período de madurez de } 3 \text { meses. } \\
\text { Busque variedades que maduren antes. }\end{array}$ \\
\hline Brócoli & $\begin{array}{l}\text { Early Green, Early Dividend, Green } \\
\text { Sprouting/Calabrese, Waltham, } \\
\text { Packman, De Cicco, Brócoli Raab } \\
\text { (Rapini) }\end{array}$ & $\begin{array}{l}\text { Coseche los extremos antes de que se abran las flores. Se desarrollan muchos } \\
\text { brotes pequeños después de que se corta la cabeza principal. Muy resistente al frío } \\
\text { y nutritivo. El brócoli Raab no se relaciona con el brócoli. }\end{array}$ \\
\hline Berenjena & $\begin{array}{l}\text { Black Beauty, Dusky, Long, } \\
\text { Ichiban, Cloud Nine (blanca) }\end{array}$ & $\begin{array}{l}\text { Necesita suelos y climas cálidos. Se cosechan en verano. Pueden necesitar estacas. } \\
\text { Fruta amarga provocada por las altas temperaturas o condiciones de sequía. }\end{array}$ \\
\hline Berza & $\begin{array}{l}\text { Georgia, Georgia Southern, Top } \\
\text { Bunch, Vates }\end{array}$ & $\begin{array}{l}\text { Tolerante al frío y al calor. Los vegetales de hojas de temporadas frías son más } \\
\text { sabrosos. Los vegetales de hoja están listos para usarse } 2 \text { meses después de } \\
\text { haberse plantado. Coseche las hojas que están más abajo; nunca quite más de 1/3 } \\
\text { de la planta de una vez. Responden bien a los fertilizantes con nitrógeno. }\end{array}$ \\
\hline Calabacín & $\begin{array}{l}\text { Verano: Early Prolific } \\
\text { Straightneck, Summer Crookneck, } \\
\text { Early White Scallop, Chayote } \\
\text { Calabacín: Cocozelle, Spineless } \\
\text { Beauty, Black Beauty, Chayote, } \\
\text { Calabaza } \\
\text { Invierno: Spaghetti, Table King, } \\
\text { Table Queen y Table Ace (bellota), } \\
\text { Waltham, Early Butternut (nuez } \\
\text { blanca) }\end{array}$ & $\begin{array}{l}\text { La calabaza de verano y el calabacín por lo general son tipos arbustivos; mientras } \\
\text { que la calabaza de invierno tiene hábitos de tipo enredadera. La calabaza es similar, } \\
\text { pero es resistente al calor y a las enfermedades y posee una cáscara dura; es similar } \\
\text { a la nuez blanca o a la bellota en sabor. Chayote es una cepa que necesita soporte. } \\
\text { Todas las cucurbitáceas tienen flores macho y hembra separadas en la planta, y se } \\
\text { necesita la polinización por parte de los insectos para la formación de frutos. Se } \\
\text { produce el cruce entre los tipos, pero solo resulta evidente cuando se guardan las } \\
\text { semillas. Las enfermedades de las hojas y las frutas son bastante habituales. Los } \\
\text { tipos de invierno se almacenan bien. }\end{array}$ \\
\hline Calabaza & $\begin{array}{l}\text { Big Max, Connecticut Field, } \\
\text { Prizewinner, Jack Be Little, Jack O } \\
\text { Lantern, Calabaza }\end{array}$ & $\begin{array}{l}\text { Necesita mucho espacio, pero se puede cultivar debajo de vegetales más altos. Se } \\
\text { necesitan abejas para la polinización. Las enfermedades del follaje y la pudrición de } \\
\text { las frutas son habituales. }\end{array}$ \\
\hline Cebollas & $\begin{array}{l}\text { Bulbo: Granex (amarilla) } \\
\text { Verde: Evergreen Bunching, } \\
\text { White Lisbon Bunching } \\
\text { Multiplicadores: Escaloñas } \\
\text { Puerro: American Flag }\end{array}$ & $\begin{array}{l}\text { Según el tipo, se pueden cultivar las cebollas con semillas, plantones, trasplantes } \\
\text { o divisiones. Las cebollas de bulbo deben plantarse durante el otoño y deben } \\
\text { ser variedades de días cortos. Las cebollas verdes o de bulbos pueden cultivarse } \\
\text { durante el otoño hasta la primavera. Plántelas cerca y coséchelas (pódelas) según } \\
\text { sea necesario. Inserte los plantones de manera recta así los tallos quedan derechos. } \\
\text { Divida y trasplante los tipos multiplicadores cada año. }\end{array}$ \\
\hline Coliflor & $\begin{array}{l}\text { Snowball Strains, Snow Crown, } \\
\text { Brocoverde }\end{array}$ & $\begin{array}{l}\text { Puede ser difícil de cultivar. Las plantas son resistentes al frío, pero las cabezas no. } \\
\text { Sujete las hojas alrededor de la cabeza (lo que se denomina blanqueo) cuando } \\
\text { tenga 2-3 pulgadas para evitar la decoloración o plante variedades que se aclaren } \\
\text { solas. }\end{array}$ \\
\hline Col rábano & Early White Vienna, Purple Vienna & $\begin{array}{l}\text { Es fácil de cultivar. Existen variedades en rojo y verde. Úselas frescas o cocidas. } \\
\text { Las hojas son comestibles. Coseche los tallos cuando tengan } 1 \frac{1 / 2}{2} \text { a } 3 \text { pulgadas de } \\
\text { diámetro. }\end{array}$ \\
\hline Col rizada & $\begin{array}{l}\text { Vates Dwarf Blue Curled, Tuscan } \\
\text { (lacinato), Winterbor, Redbor }\end{array}$ & $\begin{array}{l}\text { Buena fuente de vegetales de hoja desde fines del otoño hasta principios de la } \\
\text { primavera en el norte y la parte central de Florida. Coseche las hojas externas; pero } \\
\text { no más de } 1 / 3 \text { de la planta de una vez. Los tipos ornamentales son comestibles, } \\
\text { pero no son muy sabrosos. }\end{array}$ \\
\hline Endivia/Escarola & $\begin{array}{l}\text { Endivia: Ruffec rizado verde } \\
\text { Escarola: Hoja ancha Bátava }\end{array}$ & $\begin{array}{l}\text { Excelente ingrediente en ensaladas o puede cocinarse como cualquier vegetal de } \\
\text { hojas. Se puede reducir la amargura mediante el blanqueo } 2-3 \text { semanas antes de la } \\
\text { cosecha. La escarola (endivia Bátava) es una variedad de hoja ancha. }\end{array}$ \\
\hline Espinaca & $\begin{array}{l}\text { Melody 3, Bloomsdale } \\
\text { Longstanding, Tyee, Space }\end{array}$ & $\begin{array}{l}\text { Crece mejor solo durante los meses más fríos. Madurez rápida. Coseche la planta } \\
\text { entera o quite las hojas externas. La espinaca de Nueva Zelanda y de Malabar, } \\
\text { aunque no son las verdaderas espinacas, crecen bien durante los meses cálidos en } \\
\text { Florida. Plante espinaca de Nueva Zelanda o acelga suiza durante el verano. }\end{array}$ \\
\hline
\end{tabular}




\begin{tabular}{|c|c|c|}
\hline CULTIVO & VARIEDADES RECOMENDADAS ${ }^{1}$ & NOTAS/OBSERVACIONES \\
\hline Frutilla & $\begin{array}{l}\text { Chandler, Oso Grande, Sweet } \\
\text { Charlie, Selva, Camarosa, Festival }\end{array}$ & $\begin{array}{l}\text { Se cultivan todos los años en Florida y se comienza por las plantas sin } \\
\text { enfermedades durante el otoño. Plante únicamente las variedades adaptadas a } \\
\text { Florida. }\end{array}$ \\
\hline $\begin{array}{l}\text { Guisante, chícharo, } \\
\text { Arvejas inglesas o } \\
\text { de nieve }\end{array}$ & $\begin{array}{l}\text { Wando, Green Arrow, Sugar Snap, } \\
\text { Oregon Sugarpod II }\end{array}$ & $\begin{array}{l}\text { Fertilice a la mitad de la cantidad recomendada para otros vegetales. Demasiado } \\
\text { nitrógeno limita la producción (al igual que las temperaturas cálidas). Pueden } \\
\text { necesitar soporte según el tipo. Se deben consumir pronto después de la cosecha } \\
\text { para obtener una mejor calidad. }\end{array}$ \\
\hline $\begin{array}{l}\text { Guisante, } \\
\text { chícharo, Arvejas } \\
\text { del sur (también } \\
\text { conocidas como } \\
\text { arvejas de campo, } \\
\text { chicharillos, } \\
\text { Crowder, arvejas } \\
\text { de crema) }\end{array}$ & $\begin{array}{l}\text { California Blackeye } \text { n. }^{\circ} \text { 5, Pinkeye } \\
\text { Purple Hull, Texas Cream }\end{array}$ & $\begin{array}{l}\text { Altamente nutritivas. Fertilice a la mitad del ritmo usado para otros vegetales; } \\
\text { demasiado nitrógeno limita la producción. Es un buen cultivo de cobertura durante } \\
\text { el verano. El curculio del caupí es una plaga habitual. Mantenga el suelo húmedo. }\end{array}$ \\
\hline $\begin{array}{l}\text { Habichuelas, Frijol } \\
\text { lima }\end{array}$ & $\begin{array}{l}\text { Fordhook 242, Henderson, } \\
\text { Jackson Wonder, Dixie Butterpea } \\
\text { (moteados), Early Thorogreen }\end{array}$ & $\begin{array}{l}\text { Hay del tipo de enredadera y arbustivo; proporcione apoyo de con estacas para } \\
\text { las variedades trepadoras. Controle las chinches que dañan las vainas. Fertilice } \\
\text { a la mitad del ritmo usado para otros vegetales; demasiado nitrógeno limita la } \\
\text { producción. Ligeramente más tolerantes al calor que los frijoles enanos o de tipo } \\
\text { enredadera. Plante variedades resistentes a la oxidación. }\end{array}$ \\
\hline $\begin{array}{l}\text { Habichuelas, Frijol } \\
\text { tipo arbusto }\end{array}$ & $\begin{array}{l}\text { Ejote: Bush Blue Lake, Contender, } \\
\text { Roma II, Provider, Cherokee Wax } \\
\text { Cáscara: horticultural, pinto, } \\
\text { riñón, Habichuelas/frijol negro, } \\
\text { Habichuelas/frijol blanco, } \\
\text { garbanzo }\end{array}$ & $\begin{array}{l}\text { El frijol arbustivo madura antes y no es necesario ponerle estacas. Fertilice a } \\
\text { la mitad del ritmo usado para otros vegetales; demasiado nitrógeno limita la } \\
\text { producción. Las flores se polinizan solas. Plante variedades resistentes ala añublo } \\
\text { (moho polvoriento). }\end{array}$ \\
\hline $\begin{array}{l}\text { Habichuelas, Frijol } \\
\text { tipo enredadera }\end{array}$ & $\begin{array}{l}\text { McCaslan, Kentucky Wonder, Blue } \\
\text { Lake }\end{array}$ & $\begin{array}{l}\text { Fertilice a la mitad de la razón usado para otros vegetales; demasiado nitrógeno } \\
\text { limita la producción. Coloque un apoyo a las cepas. Pueden sembrarse con maíz } \\
\text { para el soporte de las cepas. Plante variedades resistentes al añublo (mildew, } \\
\text { hongos). }\end{array}$ \\
\hline Lechuga & $\begin{array}{l}\text { Repollada: Great Lakes } \\
\text { Mantecosa: Ermosa, Bibb, Tom } \\
\text { Thumb, Buttercrunch } \\
\text { Hoja suelta: Tipos Simpson, Salad } \\
\text { Bowl, Red Sails, New Red Fire, Oak } \\
\text { Leaf, Salad Bowl, Royal Oak } \\
\text { Romana: Parris Island Cos, } \\
\text { Outredgeous }\end{array}$ & $\begin{array}{l}\text { Los tipos de hojas crecen bien en Florida; cultive el tipo repollada solo durante los } \\
\text { meses más fríos. Sufren daños con temperaturas heladas. Las temperaturas cálidas } \\
\text { provocan que sean amargas. Siembre las semillas de manera poco profunda, ya } \\
\text { que necesitan luz para germinar. Haga una siembra intercalada de la lechuga con } \\
\text { vegetales de temporada larga o vegetales más altos. }\end{array}$ \\
\hline Maíz dulce & $\begin{array}{l}\text { Silver Queen (blanco), How Sweet } \\
\text { It Is (blanco), Sweet Ice (blanco), } \\
\text { Sweet Riser (amarillo), Early } \\
\text { Sunglow (amarillo) }\end{array}$ & $\begin{array}{l}\text { Necesita espacio; siémbrelo en bloques de al menos } 3 \text { filas para lograr una buena } \\
\text { polinización. Separe las diferentes variedades mediante la polinización cruzada. } \\
\text { Plántelo donde no haga sombra a otros vegetales. No resulta beneficioso remover } \\
\text { los retoños. Cosecharlo temprano en la mañana permite mantener el contenido de } \\
\text { azúcar. Observe si hay presencia del gusano elotero del maíz. }\end{array}$ \\
\hline $\begin{array}{l}\text { Melón tipo } \\
\text { "Cantaloupes" y } \\
\text { "Honeydews" }\end{array}$ & $\begin{array}{l}\text { Athena, Ambrosia, Galia (pulpa } \\
\text { verde) }\end{array}$ & $\begin{array}{l}\text { Se necesitan abejas para la polinización. Propenso a las enfermedades. Coloque } \\
\text { abono para reducir la pudrición de la fruta y la salmonela. Regarlo excesivamente o } \\
\text { las lluvias fuertes reducen el contenido de azúcar de las frutas maduras. Coséchelo } \\
\text { cuando la fruta se separe sin problemas de la cepa aplicando una ligera presión. }\end{array}$ \\
\hline Mostaza & $\begin{array}{l}\text { Southern Giant Curled, Florida } \\
\text { Broad Leaf, Tendergreen, Giant } \\
\text { Red, Green Wave, Mizuna }\end{array}$ & $\begin{array}{l}\text { Vegetal de hoja de buena cocción, de otoño a primavera; coseche las hojas } \\
\text { externas. Los tipos de hoja ancha necesitan más espacio. Sufren daños con } \\
\text { temperaturas heladas. Las temperaturas cálidas hacen que tengan un sabor } \\
\text { amargo. }\end{array}$ \\
\hline Nabos & $\begin{array}{l}\text { Raíces: Purple Top White Globe } \\
\text { Vegetales de hojas: Seven Top, } \\
\text { Shogoin }\end{array}$ & $\begin{array}{l}\text { Cultivo en climas fríos, de rápido crecimiento. Cultivo de raíces y partes superiores } \\
\text { (vegetales de hoja). Coloque las semillas al voleo en una fila ancha o individual. } \\
\text { Pódelas de manera temprana para permitir la expansión de la raíz. Las raíces más } \\
\text { pequeñas }\left(2^{\prime \prime}\right) \text { tienen un sabor más suave. }\end{array}$ \\
\hline
\end{tabular}




\begin{tabular}{|c|c|c|}
\hline CULTIVO & VARIEDADES RECOMENDADAS ${ }^{1}$ & NOTAS/OBSERVACIONES \\
\hline $\begin{array}{l}\text { Ocra/Quimbombo/ } \\
\text { Gumbo }\end{array}$ & $\begin{array}{l}\text { Clemson Spineless, Emerald, } \\
\text { Annie Oakley II, Cajun Delight }\end{array}$ & $\begin{array}{l}\text { Coloque las semillas en agua durante } 6 \text { horas para lograr una mejor germinación. } \\
\text { Necesita suelos y temperaturas cálidas. Muy tolerante al calor. Altamente } \\
\text { susceptible a nematodos de pudrición de las raíces. Coseche las vainas unos } \\
\text { días después de que los pétalos de las flores se hayan caído o que las vainas se } \\
\text { endurezcan y estén fibrosas. }\end{array}$ \\
\hline $\begin{array}{l}\text { Patata irlandesa/ } \\
\text { Papa }\end{array}$ & $\begin{array}{l}\text { Red Pontiac, Yukon Gold, Gold } \\
\text { Rush }\end{array}$ & $\begin{array}{l}\text { Plante } 2 \text { onzas de semillas certificadas con al menos un ojo. Cada una producirá } \\
\text { de } 6 \text { a } 8 \text { patatas. No comience con las que "se compran en las tiendas". Necesita } \\
\text { temperaturas frías, humedad y grandes cantidades de fertilizante. }\end{array}$ \\
\hline $\begin{array}{l}\text { Patata, Papas } \\
\text { dulces/Camote }\end{array}$ & $\begin{array}{l}\text { Centennial, Beauregard, } \\
\text { Vardaman, Boniato }\end{array}$ & $\begin{array}{l}\text { Comience con trasplantes sin certificado (estacas). Use los cortes de puntas de las } \\
\text { cepas en un segundo cultivo y una temporada prolongada de cosecha. Tipos: pulpa } \\
\text { húmeda (ñames) y pulpa seca (por ejemplo, boniato). Los tipos arbustivos permiten } \\
\text { conservar espacio en el huerto. Los gorgojos de las batatas son un problema grave; } \\
\text { rote el sitio de plantación. }\end{array}$ \\
\hline Pepinillos & $\begin{array}{l}\text { Slicer: Sweet Success, Poinsett, } \\
\text { Ashley, MarketMore 76, Straight } \\
\text { Eight, Space Master } \\
\text { Pickle: Eureka, Boston Picklinag }\end{array}$ & $\begin{array}{l}\text { Hay dos tipos: para rebanar y para conservar en vinagre. Los del segundo tipo } \\
\text { pueden usarse frescos. Hay variedades Burpless. Muchos híbridos son ginóceas } \\
\text { (flores hembra; solo las flores hembra producen fruta). Se necesitan abejas para la } \\
\text { polinización. }\end{array}$ \\
\hline Pimientos & $\begin{array}{l}\text { Dulce: California Wonder, Red } \\
\text { Knight, Big Bertha, Sweet Banana, } \\
\text { Giant Marconi, Cubanelle } \\
\text { Picante: Early Jalapeno, Jalapeno } \\
\text { M; Cherry Bomb, Hungarian Hot } \\
\text { Wax, Big Chile II, Mariachi, Numex, } \\
\text { Ancho, Thai, Anaheim Chile, Long } \\
\text { Cayenne, Habanero, Caribbean } \\
\text { Red Habanero }\end{array}$ & $\begin{array}{l}\text { Los trasplantes a menudo dan mejores resultados que las semillas. Resulta } \\
\text { especialmente beneficioso poner abono. Se produce a menudo en verano. Lo } \\
\text { "picante" del pimiento depende de la variedad y se mide en unidades Scoville. }\end{array}$ \\
\hline Rabanito & $\begin{array}{l}\text { Cherry Belle, White Icicle, Sparkler, } \\
\text { Champion, Daikon }\end{array}$ & $\begin{array}{l}\text { Se cultivan de manera fácil y rápida; debe podarlos de manera temprana y hacer } \\
\text { una siembra intercalada con vegetales de cultivo lento para ahorrar espacio. } \\
\text { Plántelos cada dos semanas durante la temporada de cultivo para tener un } \\
\text { suministro continuo. Los climas cálidos y la madurez excesiva ocasionan un sabor } \\
\text { picante y amargo. Los rabanitos orientales o de invierno (como los Daikon) también } \\
\text { se cultivan bien en Florida. }\end{array}$ \\
\hline Remolacha & $\begin{array}{l}\text { Tall Top, Early Wonder, Detroit } \\
\text { Dark Red, Cylindra, Red Ace, } \\
\text { Yellow Detroit }\end{array}$ & $\begin{array}{l}\text { La remolacha necesita mucha humedad en el momento de la siembra o se } \\
\text { producirá una germinación deficiente. Las hojas son comestibles. Pódelas antes } \\
\text { para que las raíces de la remolacha tengan espacio para crecer. Muy tolerantes al } \\
\text { frío. Alto contenido de vitaminas y hierro. }\end{array}$ \\
\hline Repollo & $\begin{array}{l}\text { Rio Verde, Flat Dutch, Round } \\
\text { Dutch, tipos de Wakefield, } \\
\text { Copenhagen Market, Savoy, Red } \\
\text { Acre }\end{array}$ & $\begin{array}{l}\text { Alto contenido en vitaminas, especialmente vitamina C. Temporada larga de } \\
\text { plantación durante el otoño y el invierno. Compre plantas limpias para evitar } \\
\text { la enfermedad de pudrición negra de los repollos. Necesita mucha humedad y } \\
\text { fertilizante. Tolerante a las heladas. Controle la aparición de orugas. }\end{array}$ \\
\hline Repollo chino & $\begin{array}{l}\text { Michihili, bok choy, Napa, baby } \\
\text { bok choy, pak-choi, joi choi }\end{array}$ & $\begin{array}{l}\text { Es fácil de cultivar. Hay dos tipos: Cabeza (Pekinensis) u hoja abierta (Chinensis). } \\
\text { Bok Choy es del tipo de hoja abierta, mientras que Michihili y Napa forman cabezas } \\
\text { más ajustadas. }\end{array}$ \\
\hline $\begin{array}{l}\text { Repollos de } \\
\text { Bruselas }\end{array}$ & Jade Cross, Long Island Improved & $\begin{array}{l}\text { Se necesitan climas fríos ( } 58-60 \text { F) o los repollos se abrirán y no quedarán sólidos. } \\
\text { Se recogen los repollos cuando tienen el tamaño de una nuez y están firmes. Los } \\
\text { primeros repollos cerca de la parte inferior de la planta son los que estarán listos } \\
\text { primero. Quite las hojas que haya debajo de los repollos maduros y, luego, quite } \\
\text { los repollos girándolos para sacarlos del tallo. Recoja los repollos en intervalos de } \\
\text { alrededor de } 2 \text { semanas y manténgalos refrigerados. }\end{array}$ \\
\hline Rúcula & Speedy, Astro & $\begin{array}{l}\text { Siembre en intervalos de } 2 \text { a } 3 \text { semanas desde el otoño hasta la primavera para } \\
\text { lograr una cosecha continua. Las hojas verde oscuro picantes pueden cocinarse al } \\
\text { vapor, hacerse puré (majados) o usarse frescas en ensaladas y sándwiches. Coseche } \\
\text { las hojas individuales según sea necesario o toda la planta cuando tenga una altura } \\
\text { de } 8 \text { a } 10 \text { pulgadas. Las altas temperaturas provocan que la rúcula florezca y sea } \\
\text { más amarga. }\end{array}$ \\
\hline
\end{tabular}




\begin{tabular}{|c|c|c|}
\hline CULTIVO & VARIEDADES RECOMENDADAS ${ }^{1}$ & NOTAS/OBSERVACIONES \\
\hline Sandía & $\begin{array}{l}\text { Grande: Jubilee (también } \\
\text { conocida como FL Giant), Crimson } \\
\text { Sweet, Charleston Grey } 133 \\
\text { Pequeña: Sugar Baby, Mickeylee }\end{array}$ & $\begin{array}{l}\text { Las cepas necesitan mucho espacio. Hay tipos de "ice box" más pequeños. Plante } \\
\text { variedades resistentes a las enfermedades. Se necesitan abejas para la polinización. } \\
\text { Se debe hacer una siembra intercalada de los tipos "sin semilla" con los tipos } \\
\text { habituales para que se forme la fruta. Coséchela cuando el melón debajo comience } \\
\text { a ponerse amarillo o cuando el zarcillo de la fruta se seque. }\end{array}$ \\
\hline Tomates & $\begin{array}{l}\text { Fruta grande: Celebrity, Heat } \\
\text { Wave II, Better Boy, Beefmaster, } \\
\text { BHN444-Southern Star*, Amelia*, } \\
\text { BHN 640*, Tasti-Lee }{ }^{\text {TM }} \\
\text { Fruta pequeña: Sweet 100, } \\
\text { Juliet, Red Grape, Sun Gold, Sugar } \\
\text { Snack, Sweet Baby Girl } \\
\text { Heirloom: Green Zebra, } \\
\text { Cherokee Purple, Eva Purple Ball, } \\
\text { Brandywine, Mortgage Lifter, } \\
\text { Delicious }\end{array}$ & $\begin{array}{l}\text { La colocación de estacas, soportes y abono resulta beneficiosa. Las flores se } \\
\text { polinizan solas. La caída de la floración generalmente se debe a temperaturas } \\
\text { demasiado altas o demasiado bajas o a una fertilización con nitrógeno excesiva. } \\
\text { Algunos problemas graves son la podredumbre apical, el marchitamiento, las } \\
\text { moscas blancas y los minadores. Los de tipo cereza son resistentes al calor. } \\
\text { *Resistentes al TSWV (virus del bronceado del tomate) }\end{array}$ \\
\hline Zanahorias & $\begin{array}{l}\text { Imperator, Nantes, Danvers, } \\
\text { Chantenay }\end{array}$ & $\begin{array}{l}\text { Cultive las zanahorias sobre una base elevada para obtener mejores resultados. } \\
\text { Siembre las semillas de manera poco profunda. Germinan de manera lenta. } \\
\text { Mantenga el suelo constantemente húmedo durante la germinación y los períodos } \\
\text { de cultivo. Pode las plántulas según el espacio recomendado cuando tienen una } \\
\text { pulgada de alto. Excelente fuente de vitamina } A \text {. }\end{array}$ \\
\hline \multicolumn{3}{|c|}{$\begin{array}{l}{ }^{1} \text { Hay otras variedades que pueden producir bien también. Las sugerencias se basan en la disponibilidad, el rendimiento y la resistencia a las } \\
\text { pestes. } \\
{ }^{2} \text { La información sobre la espinaca de Nueva Zelanda y de Malabar, la calabaza, el chayote y muchos otros vegetales se puede encontrar en: } \\
\text { https://edis.ifas.ufl.edu/topic_minor_vegetables }\end{array}$} \\
\hline
\end{tabular}


Tabla 3. Productos actualmente clasificados para el manejo de insectos y ácaros en huertos de vegetales en la casa.

\begin{tabular}{|c|c|c|c|c|c|c|c|c|c|c|}
\hline Peste & Neem $^{\mathrm{d}, e}$ & Spinosad ${ }^{d, e}$ & $\mathbf{B t}^{\mathrm{a}, \mathrm{e}}$ & Carbaril $^{d}$ & Malathin $^{d}$ & Piretroides $^{\mathrm{b}, \mathrm{d}}$ & Jabón & $\begin{array}{c}\text { Aceites } \\
\text { hortícolas }^{\text {ce }}\end{array}$ & Imidacloprid $^{d}$ & Acetamiprid $^{d}$ \\
\hline Ácaros & $x$ & & & & & & & $x$ & & \\
\hline Áfidos & $x$ & & & & $x$ & & $x$ & $x$ & $x$ & $x$ \\
\hline Alticinos & & & & $x$ & $x$ & $x$ & & & $x$ & $x$ \\
\hline $\begin{array}{l}\text { Barrenador } \\
\text { de la cepa de } \\
\text { calabaza }\end{array}$ & & & $x$ & & & $x$ & & & & \\
\hline Chinches & & & & & & $x$ & & & & $x$ \\
\hline $\begin{array}{l}\text { Curculio del } \\
\text { caupí }\end{array}$ & & & & $x$ & & $x$ & & & & $x$ \\
\hline $\begin{array}{l}\text { Escarabajo de } \\
\text { la patata }\end{array}$ & & $x$ & & & & & & & $x$ & $x$ \\
\hline $\begin{array}{l}\text { Escarabajo del } \\
\text { pepino }\end{array}$ & $x$ & & & $x$ & $x$ & $x$ & & & & $x$ \\
\hline $\begin{array}{l}\text { Escarabajo } \\
\text { mexicano del } \\
\text { frijol }\end{array}$ & & & & $x$ & $x$ & $x$ & & & & $x$ \\
\hline $\begin{array}{l}\text { Gusano } \\
\text { cogollero }\end{array}$ & & $x$ & $x$ & & & $x$ & & & & \\
\hline $\begin{array}{l}\text { Gusano del } \\
\text { tomate, } \\
\text { oxiuros }\end{array}$ & & $x$ & $x$ & & & $x$ & & & & \\
\hline $\begin{array}{l}\text { Gusano } \\
\text { elotero del } \\
\text { maíz }\end{array}$ & & $x$ & $x$ & & & $x$ & & & & \\
\hline $\begin{array}{l}\text { Gusano } \\
\text { melón, gusano } \\
\text { de la salmuera }\end{array}$ & & $x$ & $x$ & & $x$ & $x$ & & & & \\
\hline Minadores & & $x$ & & & & & & & & \\
\hline $\begin{array}{l}\text { Moscas } \\
\text { blancas }\end{array}$ & $x$ & & & & & $x$ & $x$ & $x$ & $x$ & $x$ \\
\hline $\begin{array}{l}\text { Oruga de la } \\
\text { col }\end{array}$ & & $x$ & $x$ & & $x$ & $x$ & & & & \\
\hline $\begin{array}{l}\text { Orugas de } \\
\text { la palomilla } \\
\text { dorso de } \\
\text { diamante }\end{array}$ & & $x$ & $x$ & & & & & & & \\
\hline Saltamontes & & & & $x$ & & & & & $x$ & $x$ \\
\hline Trípidos & & $x$ & & & & & & & $x$ & $x$ \\
\hline $\begin{array}{l}\text { Virus de } \\
\text { enrollamiento } \\
\text { de la hoja del } \\
\text { frijol }\end{array}$ & & $x$ & $x$ & & & $x$ & & & & \\
\hline \multicolumn{11}{|c|}{$\begin{array}{l}\text { La X significa que el producto es de alguna manera eficaz para controlar la plaga que se menciona. (Consulte el "ingrediente activo" en las } \\
\text { etiquetas de los productos para determinar qué pesticidas contienen los productos. También, observe los vegetales específicos para conocer } \\
\text { cuándo se puede usar el producto. Preste especial atención al período de espera indicado en la etiqueta. Este es el tiempo que tiene que } \\
\text { transcurrir entre la aplicación del plaguicida y la cosecha). } \\
\text { a Bacillus thuringiensis } \\
\text { bIncluye bifentrina, cialotrina, ciflutrina, esfenvalerato y permetrina. Las plagas y los cultivos mencionados varían según el producto. Lea } \\
\text { atentamente las etiquetas. } \\
\text { cPruebe en algunas plantas primero debido al potencial de quemadura de hojas; no lo use en climas cálidos. } \\
\text { dPara proteger a las abejas y a otros polinizadores, no aplique este insecticida cuando la planta esté floreciendo. } \\
\text { eProductos menos tóxicos }\end{array}$} \\
\hline
\end{tabular}

